\title{
Digital Neocolonialism and Massive Open Online Courses (MOOCs): Colonial Pasts and Neoliberal Futures
}

\author{
Taskeen Adam
}

South African PhD Candidate at the Centre for Development Studies, University of Cambridge, Cambridge, UK

Email: ta362@cam.ac.uk

Author Biography: Taskeen is a Cambridge-Africa Scholar pursuing a PhD on "The role of African Massive Open Online Courses in supporting the most marginalised". Taskeen pioneered Solar Powered Learning in South Africa and Mobile Education for Smart Technologies in India. She was chosen as one of M\&G top 200 Young South Africans. 


\section{Digital Neocolonialism and Massive Open Online Course (MOOC) Platforms: Colonial pasts and Neoliberal futures}

Through evaluating dominant MOOC platforms created by Western universities, I argue that MOOCs on such platforms tend to embed Western-centric epistemologies and propagate this without questioning their global relevance. Consequently, such MOOCs can be detrimental when educating diverse and complex participants as they erode local and indigenous knowledge systems. Arguing that the digital divide is an exacerbation of historical inequalities, I draw parallels between colonial education, specifically across Sub-Saharan Africa, and ‘digital neocolonialism' through Western MOOC platforms. I analyse similarities in ideology, assumptions, and methods of control. Highlighting evolving forms of coloniality, I include contemporary problems created by neoliberal techno-capitalist agendas, such as the commodification of education. Balance is needed between the opportunities offered through MOOCs and the harms they cause through overshadowing marginalised knowledges and framing disruptive technologies as the saviour. While recommending solutions for inclusion of marginalised voices, further problems such as adverse incorporation are raised.

Keywords: decolonising education, decolonising technology, digital neocolonialism, epistemic injustice, neoliberal education 


\section{Introduction}

With increasing connectivity throughout the world, there has been great optimism for democratising access to education through online education such as Massive Open Online Courses (MOOCs). Particular studies on the digital divide question this notion, illustrating that technology can exacerbate inequality as those with higher socio-economic status are able to better access and utilise the knowledge provided (Warschauer 2003). In this paper, I contextualise historical inequalities through colonialism as being key to highlighting inequalities embedded in present-day online education. Using a decolonial lens, I further highlight how coloniality, under the aegis of neoliberal agendas, poses new and complex threats. Beyond challenging the philanthropic claims of MOOC platforms as democratising access to education, I go a step further to highlight the potential dangers and epistemic injustices that such corporatized, Western platforms can propagate. I problematise these MOOC platforms, and to a lesser extent, the content, pedagogy and embedded epistemologies within some MOOCs on these platforms. Whilst acknowledging the vast and diverse manifestations of individual MOOCs, this research focuses on statistics of general trends and trajectories.

The evolution of the MOOC space and its varieties are reviewed in Section 2, with an overview of MOOCs and their equivalents in Sub-Saharan Africa. Decolonising online education requires delving into discourse from two streams; decolonising education; and decolonising technology. Thus, in Section 3, I give a brief historical analysis of colonial education across Sub-Saharan Africa, and the decolonisation of education processes currently underway. Looking at coloniality as outliving direct colonialism (Maldonado-Torres 2007), I frame decolonial discourse as tackling coloniality embedded within both colonial pasts and neoliberal futures. In Section 4, I explore discourses on digital neocolonialism, techno-capitalism and the decolonisation of technology. Finally, in Section 5, I combine these analyses to examine the 
coloniality embedded in MOOCs through digital neocolonialism, including new problems created by neoliberal techno-capitalist agendas in higher education.

In this paper, I use the term 'Global South' as a less hierarchical, non-evolutionary, counterhegemonic way (as opposed to 'developing') of describing countries subjected to the socioeconomic and political consequences of coloniality (Hollington et al. 2015; Santos 2014). The term 'Western' is similarly used beyond its geographic meaning, in the Saidian (1978) sense, to also refer to Occidental cultures and epistemologies (Santos 2014). Neither of the terms are holistic but are used for lack of better terminology to highlight geo-political and culturalepistemic inequalities. It is also noted that, with the rise of a global elite, such terminologies can hide intra-country inequalities.

\section{The Evolving MOOC Space}

MOOCs, originally an extension of the Open Educational Movement (OEM), vary considerably in implementation based on whether they are for profit, free to access, open source, have certification fees, and/or carry institutional credits. Within universities, some MOOCs are 'inward' facing, serving existing, registered students, and others are 'outward' facing, geared to the general public (Czerniewicz et al. 2014). A 2018 analysis found that over 11400 MOOCs exist, with 101 million students, and partnerships with over 900 universities (Shah 2018).

MOOCs were generally classified as XMOOC (eXtended MOOCs) or cMOOC (connectivist MOOC), although they now lie on the spectrum between the two taxonomies. cMOOCs typically utilise horizontal, connectivist pedagogies, such as P2PU. Though embracing openness and multi-directional communication, criticism of cMOOCs is that learning becomes too unstructured and chaotic with floods of information (Liyanagunawardena, Williams, and Adams 2013). xMOOCs, focused on in this paper, tend to be structured around instructivist, 
lecturer-centric teaching recorded in a digital form, where knowledge of predefined learning objectives is transferred didactically and assessed predominantly through automated grading (Patru and Balaji 2016, 54). As of 2018, at least 41 xMOOC platforms were showcased on Class Central (Shah 2018), and 108 on MOOC List (MOOC List 2018). Interestingly, no Chinese MOOC platforms were mentioned on either website although MOOC platforms of other languages were listed. The most popular xMOOC platforms originate from elite institutions or from Silicon Valley corporations (see Table 1).

Further variations of MOOCs exist such as Small Private Online Courses (SPOCs), Regional Open Online Courses (ROOCs) and blended learning models, showing the evolution of MOOCs (Patru and Balaji 2016). Whilst not being much competition for the major corporatised MOOC providers from the US and UK, various 'regional' MOOC platforms have emerged since 2015, supporting other countries and languages: e.g. XuetangX (China), MiríadaX (Spain), MéxicoX (Mexico), France Université Numérique (France), EduOpen (Italy), ThaiMOOC (Thailand), SWAYAM (India), and Edraak (Jordan) (Shah 2017). These platforms are termed 'country-specific' and 'regional' while the platforms from the US and UK are termed 'global' because they are in English (Shah 2017), reinforcing the narrative that to be global is to be Western. The OpenedX platform has made it possible for approximately 1600 small-scale MOOC platforms to exist (Future Trends Forum 2018), but also embeds edX's lecturer-centric pedagogy into these platforms. XuetangX from China has interestingly completely revamped the OpenedX backend and offers a re-envisioning of the MOOC space, offering a bustling community section and a channel for self-produced content (Shah 2016). 
Table 1 List of Major MOOC Platforms on Class Central (Shah 2018)

\begin{tabular}{|c|c|c|c|}
\hline Platforms & Founding Partners & Students & Additional \\
\hline Coursera & $\begin{array}{l}\text { Stanford University, } \\
\text { University of Pennsylvania, } \\
\text { and John Hopkins University }\end{array}$ & $\begin{array}{l}\approx 37 \\
\text { million }\end{array}$ & $\begin{array}{l}\text { - New paid subscription model } \\
\text { - Offers an iMBA } \\
\text { - Partnered with Google, World } \\
\text { Bank, CISCO, BCG, Intel }\end{array}$ \\
\hline edX & $\begin{array}{l}\text { Massachusetts Institute of } \\
\text { Technology, Harvard } \\
\text { University, and UC Berkeley }\end{array}$ & $\begin{array}{l}\approx 18 \\
\text { million }\end{array}$ & $\begin{array}{l}\text { - Not for profit and open source } \\
\text { - High partnering fees } \\
\text { - Partnered with Microsoft, IBM } \\
\text { - Lecturer-centric } \\
\text { - Micro-masters }\end{array}$ \\
\hline XuetangX & Tsinghua University & $\begin{array}{l}\approx 14 \\
\text { million }\end{array}$ & $\begin{array}{l}\text { - Facilitates students self- } \\
\text { produced content } \\
\text { - Focus on interactivity } \\
\text { - Blended learning 'rain } \\
\text { classroom' }\end{array}$ \\
\hline Udacity & $\begin{array}{l}\text { Stanford University, Google, } \\
\text { Facebook, AT\&T }\end{array}$ & $\begin{array}{l}\approx 10 \\
\text { million }\end{array}$ & $\begin{array}{l}\text { - Commercial revenue model } \\
\text { - Nano-degree program } \\
\text { - Partners include BMW, } \\
\text { Amazon, IBM }\end{array}$ \\
\hline Futurelearn & Open University & $\begin{array}{l}\approx 8.7 \\
\text { million }\end{array}$ & $\begin{array}{l}\text { - Student-centric } \\
\text { - Top } 200 \text { universities can access } \\
\text { - Many specialist organisation } \\
\text { partners }\end{array}$ \\
\hline $\begin{array}{l}>28 \text { other } \\
\text { platforms }\end{array}$ & & $\begin{array}{l}\approx 13.3^{*} \\
\text { million }\end{array}$ & $\begin{array}{l}\text { - 'Regional' and 'Country- } \\
\text { specific' } \\
\text { - Majority use OpenedX }\end{array}$ \\
\hline
\end{tabular}

\subsection{MOOCs in Africa}

To date, very few MOOCs from Africa exist, and no distinct MOOC platform from Africa exists. The underlying reasons for this will be discussed in Section 5. Currently, MOOCs relating to Africa are produced in one of three ways. Firstly, MOOCs from a few highly-ranked African universities, such as University of Cape Town (UCT), are able to be hosted on popular platforms like Coursera. If the university is not top-ranked but has sufficient funding, they may pay for membership on platforms such as edX (Bayes-Brown 2014), as in the case of University 
of Witwatersrand (Wits). Other avenues for universities that are not top-ranked include joining as a 'centre of excellence' on Futurelearn (FutureLearn 2019).

In the second case, a US or European institution partners with an African institution to cocreate the MOOC with the funding and branding from the former. One such example is between Open University and TESSA (Teacher Education in Sub-Saharan Africa) in the 'Making Teacher Education Relevant for 21st Century Africa' course on Futurelearn (FutureLearn 2018b). As well-intentioned as such partnerships can be, power imbalances can be problematic as funding rules and foreign methodology can be asserted by the former onto the latter. Thiong'o (2005) problematises such a relationship where data is collected by the 'native informants; call them research assistants', whilst the methodology and theorisation is done by the 'colonial intellectual' according to their 'conceptualisation of the world'.

The third case is MOOCs created about Africa by a Western university, without any partnership to an African institute. In some cases, Africans may be included as subjects of research through interviews, or in footage of unnamed impoverished families, but not as collaborators who can influence what questions are asked or shape the production of the MOOC. One example of this is the University of Aberdeen's 'Africa: Sustainable Development for All?' MOOC (FutureLearn 2018a). A more extreme example is that of the Federal Institute of Technology in Lausanne's MOOC 'African Cities 1: Introduction to Urban Planning' (Coursera 2018), omitting even to interview Africans. This can lead to stereotyping and stigmatising. Using a keyword search on Class Central (a MOOC search engine) for MOOCs with 'Africa' in the title, nine out of twelve courses running in 2018 were created from universities outside of Africa; the remaining three were from South African universities.

Considering increasing intra-country inequalities and a growing global elite, one's geographical location differs from one's social ranking in terms of privilege, thus, the argument 
here is not that all MOOCs relating to Africa need to come exclusively from its geographic location. Using Grosfoguel's $(2007,213)$ notion of ‘epistemic location' over whether someone resides within that place or not, I argue that marginalised voices of these 'epistemic locations' need to be predominantly heard. If not, which is the present case, there is the risk of others writing their history. Santos (2014) similarly argues for engagement with ways of knowing from those who have systemically suffered injustices through colonialism, capitalism and patriarchy. He terms these 'epistemologies of the South'. Given the recent colonial past, this is more reason for those marginalised to reclaim their histories and knowledges.

In terms of MOOC platforms from Africa, there are no precise examples. The National Open University of Nigeria promises some MOOCs, but none are currently available. Many private universities and corporations offer paid courses, with parts of, or entire courses free, such as SlateCube and Beni African University in Nigeria. In the commercial space in South Africa, Hyperion Development offers paid mentor-led online boot camps. Getsmarter, also South African, offers paid online courses from prestigious universities. Neither is adapted to nor caters for the local marginalised communities. Udemy, although for-profit, is built in Turkey and has a strong culturally diverse approach with low-cost courses from people in all parts of the world, also putting a variety of local languages online. One can learn Twi from Ghana, isiXhosa from South Africa, or even Tongan from the Kingdom of Tonga in Polynesia (Udemy 2018).

With privatised education models increasing in higher education across Africa in general, the e-learning space is also seeing an increase in private providers (Trines 2018). Although it goes against principles of openness, it generates revenue for locally-relevant courses to exist in that context. Lockley (2018) highlights that 'openness' is defined in and for Western contexts, and should not be thought of as an absolute requirement when viewed in light of the global inequities in power and privilege. The following section thus looks at colonial influences on 
education, which will provide the framing on which to analyse the coloniality embedded within MOOCs through digital neocolonialism.

\section{Decolonising Education}

\subsection{Colonial Education}

History, culture, identity and politics are integral to the education narrative and thus cannot be separated. This paper argues that present-day inequalities in online education stem from historical injustices in education. The methods of implementation of colonial education differed from country to country. For example, the 1953 Bantu Education Act in Apartheid South Africa limited the type of knowledge a black person would receive, limiting their life opportunities. Hendrik Verwoerd, the Minister of Native Affairs in South Africa summarised the intended type of 'partial' education that Bhabha (1994, chap. 4) spoke of:

'There is no place for [the Bantu] in the European community above the level of certain forms of labour ... What is the use of teaching the Bantu child mathematics when it cannot use it in practice? That is quite absurd. Education must train people in accordance with their opportunities in life, according to the sphere in which they live.' (Lapping 1987, 109)

Whilst this quote is specifically about Apartheid South Africa, it bears resemblance to colonialism in other colonised territories. Due to brevity, the vast discourses on, and nuances of, colonial education, particularly in Africa, cannot be unpacked in detail here but can be found in the works of Thiong'o (1986), Mamdani (1996), Mbembe (2016) and many others. The common trait was that such education was to serve the interest of colonial powers, directly or indirectly; it aimed to convince the colonised to think of the coloniser - his epistemologies, his philosophies, his policies, his languages, his cultures - as superior. This colonisation of the 
mind is still deeply embedded in previously colonised countries, decades after formal political independence.

\subsection{Decolonisation of Education}

One of the main aims of decolonial movements was decolonising the mind through reclaiming identities and lost humanities. Language is key to reclaiming identities and Thiong'o (1986) asserts that true freedom can only be achieved when we reclaim African languages, as these languages embody culture and heritage. Similarly, Dei and Simmons $(2010,9)$ discuss the need for 'decolonisation at the level of discourse' that problematises the 'Eurocentric prisms' through which discourse is framed, making it hard to oppose inbuilt 'hegemonic form, logic and implicit assumptions'. A decolonised space deals with the 'spiritual and emotional harm' (Dei and Simmons 2010,9) that schooling can cause on the oppressed through the negation and 'amputation' of parts of themselves (Dei and Simmons 2010,16). This creates a space where a plurality of voices, experiences, histories, epistemologies and knowledges can be legitimised, claimed and celebrated. Plurality for plurality's sake, however, is not always valuable. Makgoba and Seepe $(2004,22)$ warn that the aim is not simply for multiracialism, but for a true dismantling of power and privilege.

For Fanon, one of the founding decolonial thinkers, education is the solution. The education he envisioned involved 'opening their minds, awakening them, and allowing the birth of their intelligence' (Fanon 1961, 159). Freire (1970, 35) called this a 'critical consciousness'. Yet, the end-goals of decolonising education remain under debate. Andreotti et al. $(2015,23)$ categorise the enunciations of decolonisation in higher education across a spectrum: 'soft reform', ‘radical-reform', and ‘beyond-reform'. ‘Soft-reform' deals with individual change and inclusion of diversity without addressing structural and power imbalances. 'Radical-reform' deals with epistemological dominance, tackling systemic problems through attempting to 'fix' unequal systems. The critique of this is that fixing such systems can strengthen them and work 
against enabling alternatives to such systems. 'Beyond-reform' addresses ontological dominance, where prioritisation is given to different ways of being over mere inclusion of different ways of knowing. This group sees the modern global capitalist system as unsustainable, inherently violent and irrecoverable, thus, focus efforts on building alternatives.

Practical methods of decolonisation of education are debated as much as its purpose. Jansen (2017, 163-67) highlights some of these variances, of which I draw on three. The first argues for an absolute replacement of European knowledge by local indigenous knowledges. This extreme stance allows for marginalised knowledges to be reclaimed but runs the risk of nativism and fundamentalism. The second argues for the decentring of European knowledge and recentreing of local and indigenous knowledges. The caution with this is romanticising local and indigenous knowledges as beyond critique. The last stance argues that knowledges are entangled and inseparable in a way that is not regional, but rather travelling across space, and evolving with time. Such knowledges can be critically engaged with thematically rather than regionally. Drawing on Jansen's work, my stance is that the three variances form a process. The end goal should be a space for critical and dialogical learning, however, the first and second movements are crucial building steps, as marginalised epistemologies first need to be acknowledged and established on their own terms before they can be challenged and contested with others. Vaditya $(2018,272)$ highlights this importance of 'situated knowledge building process' to help marginalised groups overcome epistemic oppression.

\subsection{Dual Identities}

The aftermath of colonialism left a legacy of confused identities and cultures. Bhabha (1994, 133) argues that the colonised subject is 'neither one nor the other', but rather a hybridised identity of otherness of the self. Hybridity happens at the level of race, language, literature, culture and religion and occurs in various intensities and forms. Grosfoguel $(2011,6)$ argues that 'the success of the modern/colonial world system consists in making subjects that are 
socially located in the oppressed side of the colonial difference, to think epistemically like the ones on the dominant positions.' This point is increasingly important today with the rise of a global elite and expanding intra-country inequalities, in addition to geo-political divides.

The education that African students receive today should neither be Eurocentric nor that of precolonial identities, as neither fits the present-day identity. The experiences of colonialism, whether lived or inherited, are now part of the history of those cultures and nations, and consequently, their education systems. Beyond focusing on what should be included or excluded, greater attention should be given to critical pedagogies that interrogate settled knowledges and create questioning approaches to knowledge (Freire 1970). Additionally, as important as discussions on the politics of culture and power are, they should be analysed in conjunction with the neoliberal agenda of commodification, capitalisation and industrialisation of education models effecting the entire globe presently (Enslin and Horsthemke 2016).

\subsection{Coloniality and Neocolonialism}

An important distinction between colonialism, the policy and practice of exploiting political and economic control over another country, and coloniality is necessary to frame neocolonialism (Maldonado-Torres 2007, 243):

'Coloniality, instead, refers to long-standing patterns of power that emerged as a result of colonialism, but that define culture, labour, intersubjectivity relations, and knowledge production well beyond the strict limits of colonial administrations. Thus, coloniality survives colonialism. It is maintained alive in books, in the criteria for academic performance, in cultural patterns, in common sense, in the self-image of peoples, in aspirations of self, and so many other aspects of our modern experience."

Maldonado-Torres $(2016,440)$ thus defines decoloniality as: 
'...the dismantling of relations of power and conceptions of knowledge that foment the reproduction of racial, gender, and geo-political hierarchies that came into being or found new and more powerful forms of expression in the modern/colonial world.'

Decoloniality thus encompasses a resistance to neocolonialism and neoliberalism in the 'modern/colonial capitalist/patriarchal world-system' as much as it is a response to direct colonisation (Grosfoguel 2007, 219). Mbembe $(2016,30)$ uses this decolonial approach to analyse neoliberal forces in education:

'We need to decolonize the systems of access and management insofar as they have turned higher education into a marketable product, rated, bought and sold by standard units, measured, counted and reduced to staple equivalence by impersonal, mechanical tests.'

Thus, coloniality manifests itself within the neoliberal agenda of commodification, capitalisation and industrialisation of education models effecting the entire globe presently, and as the following section argues, technology is one of its main propagators.

\section{Decolonising Technology}

In this paper, I define digital neocolonialism as the use of information technology and the internet by hegemonic powers as a means of indirect control or influence over a marginalised group or country. Hegemonic powers need not be a nation state as in colonialism but could be a corporation or institution. Digital neocolonialism is a form of economic, social, or cultural hegemony; it attempts to control a community, exploit it economically, and erase its identity (Martini 2017). Similar discourses include cyber-colonialism/cyber imperialism centred around the dangers of forced dependence on information technology from digitally-advanced countries (Danezis 2014), and data colonialism focusing on ethics in the collection and use of data (Model View Culture 2016). Technology colonialism (Simmons 2015) and techno- 
capitalism (Suarez-Villa 2009, 3) focus on 'corporate power' and 'exploitation of technological creativity' in the contemporary knowledge economy. For example, the ubiquitous impact of platform capitalism via companies like Amazon, Google, Facebook, Ali Baba, Uber and others, have captured the market share and formed monopolies, using mergers and acquisitions of smaller companies to feed their data needs and to eliminate competition (Srnicek 2017). Such platform models have an insatiable need for more data and will go to lengths to get it, infringing on privacy or workers' rights (ibid.).

Through pre-defined notions of progress set by the United Nations (Ulrich 1992), democratisation of access to technology has become an urgent necessity without questioning the essence of technology itself: 'democratization without a corresponding ontological transformation will just end up replicating and reifying the technological understanding of being' (Thomson 2001, 67). Describing the technological understanding of being, Heidegger (1977) warned of a time when calculative thinking might someday come to be the only form of thinking, and we can see this with the rise of technocracy and its associated technopolitics (Kurban, Peña-López, and Haberer 2017). Giving weight to Heidegger's warning, the theory of technological determinism contends that technology is a main driver of social change (Walters and Kop 2009). While some argue that this theory removes human agency, the reality is that it is becoming increasingly difficult to opt out of a pervasive technological existence. Whilst vast amounts of literature focus on who is left out by the digital divide and the new big data divide, adverse incorporation into these 'global' systems receive far less attention (Hickey and du Toit 2013).Technology is changing what we know, as well as how we come to know it (Laurillard 2008), which leads to the amplification of epistemic injustices.

Discourses problematising systemic inequalities embedded in information technology include decolonial computing, critical software studies, and critical algorithm studies. Using critical race studies, feminist theory, and decolonial perspectives, such discourses push beyond simply 
isolating the problems to its use and content, to discussions of who creates information technology, who its designed for, and the 'embeddedness of coloniality - that is, the persistent operation of colonial logics' (Ali 2017). These critiques focus on who has power, who has agency, and whose agendas are promoted, through analysing how information technology is developed, distributed and capitalised (Martini 2017).

Decolonising technology aims to destabilise hegemonic, capitalistic, and neoliberal practices embedded in technology through subversively turning it into tools for resistance and liberation. The level at which technology should be used in decolonial futures varies widely between scholar-activists, ranging from seeking a re-envisioning of the uses of technology in our lives through 'radical-reform', to taking a more weary anti-technology, 'beyond-reform' stance (Feenberg 1999; Heidegger 1977; Illich 2001).

\section{Digital Neocolonialism and MOOCs}

The following sections analyse the coloniality embedded in MOOCs, including contemporary problems brought on by neoliberalism such as the commodification of education and learners. These sections do not mean to imply that digital neocolonialism through MOOCs is the same as colonisation of education in the colonial era, but that it stems from it and shares fundamental traits. This lens of analysis is crucial as global markets are shifting from predominantly manufacturing and commodity-based economies, to a qualitatively different, new knowledge economy of data, technology and networked societies which control global power.

\subsection{Parallels in Ideology and Assumptions}

\section{Humanism and the Archetypal Student}

When colonialists infiltrated Africa in the $19^{\text {th }}$ century, they brought with them the European ideal of humanism, i.e. the Universal Man. As Africans did not conform to European notions of culture and civilisation, they were made to feel inferior and treated like 'a child' that needed 
to be educated and civilised (Fanon 2008, 15). Sharing similarities to Fanon (1961), Knox $(2016,51)$ redefines humanism as 'the unproblematised assumption of the existence of a rational and autonomous 'Man' of the Enlightenment Period, conceived in Europe and assumed to be universal in physical and cognitive form'. Knox $(2016,109)$ argues that xMOOCs aim to refine learners into an archetypal (Western) human being, who is assumed to think in a specific reasoned way, is digitally savvy, and who seeks independence and autonomy: 'a single identity with the capacity for rational self-direction'.

The humanist focus on individualism impacts MOOC pedagogy and assessment. MOOC assessment methods, for example, focus on 'what' students have learnt through automated testing, rather than the process of learning, and the effects of this learning. Such methods assume a particular type of teaching, a particular type of assessment, and a particular type of learner. Cottom $(2015,9)$ describes these learners as 'roaming autodidacts... a self-motivated, able learner that is simultaneously embedded in technocratic futures and disembedded from place, culture, history and markets. The roaming autodidact is almost always conceived as western, white, educated and male.'

True inclusion and plurality of knowledge cannot be achieved in MOOCs when difference is rejected. As the world becomes increasingly homogenised through globalisation of western frameworks, the 'multitude' - the irreducibility of complex populations - becomes a threat to standardisation and scalability (Knox 2016, 132). Thus, while xMOOCs strive for interconnectness and world wide availability of knowledge, they become a paradox as they tend to limit the ideals and aims of emancipatory and affirmative education, the very thing they claim to overcome (Knox 2016, 16). When MOOCs commit to a humanist ideology, they reject difference and fail to attend to the inclusion of different ways of thinking, knowing and being: the potential value of diverse global populations. 


\section{The Core to Periphery Model}

In terms of colonial and apartheid architecture, infrastructure in Africa was built to serve the core; their European colonisers (Mbembe 2016). The architecture of the internet today is comparable as it is designed to serve those in power through its global digital network (Knowledge Commons Brasil 2014). xMOOCs platforms, in particular, are criticised for promoting a predominantly one-way transmission of standardised knowledge from Western countries to a diverse and complex pool of 'awaiting' participants (Patru and Balaji 2016, 11; Knox 2016, 82). This is based on assumptions that the Global South is both 'deficient in education' and knowledge, and requires 'elite institutional provision' (Knox 2016, 83). These assumptions devalue the worth of an online participant, and failure to include dialogic bidirectional pedagogy further silences these peripheral voices (Freire 1970). The physical space of the Western university is where 'teaching is broadcast' and the online space is for mere consumers as observers (Knox 2016, 186).

xMOOCs tend to emphasise the physical place of learning as the site of learning for university, often for branding purposes (Hollands and Tirthali 2014). One example of this is the introduction video for 'Africa: Sustainable Development for All?' on FutureLearn which opens with an older European woman speaking about Africa, with the University of Aberdeen as the backdrop. It then goes on to show pictures from Africa whilst emphasising how the course will give access to experts at the University of Aberdeen. The course does not intend to, but it creates a subject-expert vs subject divide. Despite the topic being Africa, the centring of the University of Aberdeen would make an African participant feel that that is where knowledge lies, and theorisation happens, rather than where they are. This creates a craving in the learner to attend a university that is foreign to them, very much like the mimesis experienced in colonialism (Bhabha 1994, chap. 2). 


\section{Superiority of Knowledge and Epistemology}

Fanon $(2008,113)$ exposed how the superiority of Western man and Western knowledge was propagated even in children's books, created by 'white men for little white men'. The protagonists and heroes were always white whilst the 'the Wolf, the Devil, the Evil Spirit, the Bad Man, the Savage' was symbolised by the negro character (ibid.). Children were thus indoctrinated to see their own values and practices as inferior and to aspire to European ideals, before even interacting with a European. This inferiority complex led the colonised to attempt to replicate the white man, which began the loss of culture and pre-colonial African knowledge (ibid.). Fanon concluded that to remove such traumatisation, magazines, songs, history texts and educational material would need to be created for black children, explaining that the "view of the world is white because no black voice exists' (Fanon 2008, 118). This reflection holds true in the realm of Western MOOCs where only $1.7 \%$ and $1.1 \%$ MOOC producers are black on Coursera and Futurelearn respectively (Lockley 2018, 150).

Said (1978) outlines that knowledge was legitimatised through a European's interpretation of it rather than its own narrative and ownership. Derry (2008) similarly argues that whilst technology-enhanced pedagogies are continually improving (such as through interactivity and scaffolding), little attention is paid to the question of knowledge, i.e. their epistemologies, which are rooted in Western-centric thinking. MOOCs from elite universities assume that their knowledge is superior to knowledge from other places. This can be seen in the promotional materials of edX and Coursera which advertise a 'world class education' from the 'best professors' at 'top universities'. Portmess $(2013,3)$ aptly observes, 'such language with its implicit condescension toward non-affiliated institutions in the U.S. or abroad encourages Udacians, edXers and Courserians, to enrol not only in online, branded courses but to be coopted by the interests of powerful institutions in their own educational positioning'. Additionally, university ranking systems define 'educational excellence' according to elite US 
contexts, neglecting cultural, socio-political or infrastructural contexts in other regions. Such models are designed to 'favour the mainstream, the traditional, and the already privileged' (Bali and Sharma 2017, 26). Open knowledge thus 'redoubles' the 'epistemic alienation' through reinforcing the use of Western knowledge as "normative models, to the detriment of local epistemologies' (Piron et al. 2017).

\section{Superiority of Language and Culture}

As Fanon $(2008,25)$ described, 'To speak a language is to take on a world, a culture'. Europe planted itself in Africa's memory such that it would live on long after decolonisation (Thiong'o 2005). This was accomplished first through renaming of the landscape, then renaming the people, and finally, capture of intellect through imposing European languages: 'Language is means of organising and conceptualising reality, but it is also a bank for the memory generated by human interaction with the natural environment' Thiong'o (2005, 158). A change of language means a loss of that language's memory bank as well as its conceptual frameworks.

Of approximately 9600 MOOCs in existence today, more than half are produced in English, followed by Mandarin Chinese and Spanish ${ }^{1}$. With this epistemic violence through language loss, the potential for a pluralistic global knowledge base vanishes to a handful of dominant languages and cultures. With increasing globalised education, global MOOC participants leave their own local educational practices such as methods of inquiry and epistemology, and their local languages and culture become endangered. Even when MOOCs are translated to other languages, 'the methodological and intellectual orientations of the English-speaking academic culture' remain (Altbach 2014, 6). On the production side, the dominance of English in MOOCs also has an impact whereby they may 'inhibit the emergence of a local academic culture, local academic content, and courses tailored specially for national audiences' (ibid.).

\footnotetext{
${ }^{1}$ This was determined by the author through approximations from information provided on Class Central (Shah 2017). At least 5100 MOOCs are produced in English.
} 


\section{Superiority of Technology}

Ulrich (1992, 309) asked whether technological progress was not just a 'new, less recognizable, and therefore more effective, stage in Western imperialism' where the declared 'developing countries' are told they are 'partners in progress'. He further questions whether it is just bringing about further 'destruction of nature and a modernized form of poverty' (ibid.). The notion of technological progress has reshaped what the goals of education are, i.e. privileging science, technology, and its associated epistemologies above all else (Ulrich 1992). MOOC platforms assume that technology provides an unproblematic solution to educational demands, where access is deemed to be 'simply a matter of accessing an internet connection' (Knox 2016, 90). However, the egalitarian concept of the MOOC is based on disproportionate access, which in fact increases the digital divide (Knox 2016, 91; Patru and Balaji 2016, 25). By promoting themselves and technology as a superior form of education, MOOCs render national educational systems as well as local and indigenous knowledges as secondary (Knox 2016, 93). Rather than a focus on the development of marginalised knowledges, focus is given to accessing Western resources.

\subsection{Parallels in Control}

\section{Limited Access to and Production of MOOCs from the Global South}

In colonial times, who had access to education, and what level of access, was limited by the colonisers as they feared such education would be used against them (Mamdani 1996). Although MOOC platforms philanthropically claim to promote democratised access to 'global' knowledge (Rohs and Ganz 2015), those who are able to access them still tend to be privileged, educated and male. An analysis of 76 edX MOOCs run in 2013 and 2014 found that $71 \%$ of participants had a bachelor's degree or higher, $69 \%$ were male and $69 \%$ originated from developed countries (Patru and Balaji 2016, 39). Christensen et al. (2013) state similar findings from a review of 32 MOOCs on Coursera, reporting that $79.4 \%$ of students had a bachelor's 
degree or higher. A report from Harvard and MIT stated, based on a review of 64 of their MOOCs, that MOOC participants from the US were more affluent than the average US citizen and came from better neighbourhoods (Hansen and Reich 2015). The study further asserted that MOOCs are exacerbating rather than reducing inequalities in educational outcomes. Thrun, founder of Udacity, similarly stated MOOCs inability to support disadvantaged students in the US: 'it's a group for which this medium is not a good fit' (Lockley 2018, 148). If MOOCs cannot help the disadvantaged in the US, its own society, their ability to help other countries is questionable. Thus, whilst Coursera reported that $45 \%$ of its then 24 million participants came from the Global South (Cheney 2017), they were still mainly the educated and more well-off, whether within the US or elsewhere.

In terms of level of access, MOOCs resemble 'partial' colonial education (Bhabha 1994, chap. 4), in that the educational experience is limited. Whilst MOOCs aim to provide this partial education to the masses, the privileged still get the full educational experience at universities. Access is deemed as being allowed a snapshot into another world, rather than a place that one truly belongs in: Mbembe $(2016,2)$ highlights:

'But when we say access, we are not simply thinking in demographic terms, although these are crucial. When we say access, we are also saying the possibility to inhabit a space to the extent that one can say, 'This is my home. I am not a foreigner. I belong here'. This is not hospitality. It is not charity.'

Belonging to a place means being able to contribute. Analysis of MOOC production shows that it is managed by 'white staff members primarily from the Global North' (Lockley 2018, 150). In an analysis of MOOC production on Coursera, undertaken by the author in 2017, only 8 of the 25 participating countries were from the Global South, 15 out of the 100 university partners were Global South countries, and 164 of the 2240 courses (7.3\%) were from the Global South. 
The question arises as to why the Global South countries do not participate more in MOOC production on dominant MOOC platforms or their own alternatives. The limitations are structural. Platforms such as edX, for example, require exorbitant partnering fees, while FutureLearn accepts only the top 200 universities (mostly Western), with few exceptions. Additionally, the production costs of creating a MOOC mean that less affluent universities cannot participate. In some cases, partnerships are made with universities in the Global North which can lead to unequal power relations. This low level of production thus limits such countries from becoming equal contributors and adapters to the global knowledge base, instead becoming consumers of Western knowledge, methods, and practice (Czerniewicz et al. 2014).

\section{Regulation and Exclusion}

In removing the violence of colonial education, Fanon $(1961,162)$ supported ground up initiatives rather than those that are 'parachuted down from above'. Western MOOC platforms, however, tend to view themselves as custodians of knowledge and thus become regulators in modes of thinking and being. Dei and Simmons $(2010,8)$ term this the "normalisation of violence of education' where the teacher's role is to 'regulate the way that the world "enters into" the student', thus limiting 'authentic thinking' and 'indoctrinating them to adapt to the world of oppression'. Similarly, Knox (2016, 130-31) criticises the oft-used term "“correct" involvement' in MOOCs, as it rejects difference, regarding it as 'abnormal' and 'deviant'. Students who participate very little are negatively termed 'lurkers', when that could be the way they learn best (Knox 2016, 143). Knox $(2016,161)$ terms this 'immunisation', defined as the regulation of the external and unfamiliar rather than acknowledging and embracing difference. However, MOOC completion rates tend to be $6.5 \%$ to $7.5 \%$, indicating that the presumed normative student is not a representation of the majority of students. In fact, the 'lurker' is a better representative of the majority (Knox 2016, 143). 
MOOCs have moved far away from the open access promoted by the Open Education Movement (OEM) regarding the legal '5 R's framework' of being able to remix, revise, reuse, retain and redistribute educational resources (Wiley 2011). Portmess $(2013,2)$ noted that 'MOOCs reflect institutionalised patterns of power and authority' in how they regulate access to knowledge. Who is allowed access to MOOCs, and who gives this access, expands the digital divide and creates unequal power relations. Countries such as Crimea, Sudan, Iran, Cuba, Syria, North Korea and Somalia, for example, have faced bans from accessing MOOCs due to US sanctions (Ware 2014; Lockley 2018). Thus, the US has control over who can access 'open' education and who cannot, as they host the major servers of edX and Coursera. Even FutureLearn in the UK has adhered to US regulations (FutureLearn 2017). Additionally, due to the server locations of many platforms, the US government has access to data. Even when new MOOC platforms are created in other parts of the world, using OpenedX for example, they are most likely hosted through Amazon Web Services. Currently, there are no Amazon servers on the African continent.

\subsection{Commodification and Capitalism}

\section{Commodification of Education}

Moving to newer forms of coloniality, neoliberal capitalism poses a distinctive set of contemporary challenges that affects all parts of the world, although in different ways. Mbembe $(2016,4)$ aptly describes how this complicates the complexity of decolonisation:

The harder I tried to make sense of the idea of 'decolonization' that has become the rallying cry for those trying to undo the racist legacies of the past, the more I kept asking myself to what extent we might be fighting a complexly mutating entity with concepts inherited from an entirely different age and epoch. 
In the age of techno-capitalism and the influx of venture capitalists in the education technology industry (Schlosser 2016), Holmwood (2013) outlines how MOOCs have unbundled lecture content from tutorial support in order for the latter to be turned into a for-profit industry.

Furthermore, 2017 saw MOOCs, in their peak of popularity and market capture, parting from their promises of 'democratising access' through free online courses and a vision of a future world that seeks skill over accreditation (Shah 2018). Instead, MOOCs are trending towards selling paid courses and degrees that offer some sort of university accreditation (ibid.). Whilst MOOC platforms profit from courses, partnerships and subscriptions, MOOC designers tend to create this free content over-and-above their remunerated work. Given heighten precarity in higher education due to increased non-tenured and casual work, this model extorts academic labour while MOOC platforms capitalise off their efforts. Lockley $(2018,149)$ argues that the MOOC phenomenon of democratising education for all was just a case of 'fake public goods and interest convergence'. With large portions of the market captured, the next phase of monetisation began, contradicting their founding principles.

Through economies of scale, the scalability of standardised education such as MOOCs is viewed as positive in terms of economic efficiency (Walters and Kop 2009). This economic efficiency is normally at the expense of educational outcomes, as the ideal learning conditions for a learner, particularly a diverse pool of learners, are hard to achieve in a mass education system (Laurillard 2008). In this technological understanding of being, the industry-driven, 'banking' knowledge economy focuses on instrumental, commodified education that does not seek to nurture a 'critical consciousness' for a 'liberating education' (Freire 1970, 35 \& 79). Drawing from Heidegger, Thomson's $(2001,142)$ point that 'we have come to instrumentalize, professionalize, vocationize, corporotize, and ultimately technologize education' is now more than ever evident in MOOC platforms. 
In recent years, MOOC platforms have made concerted efforts to reach diverse markets (Cheney 2017), however the methods in which this is done is not always beneficial. Lane and Kinser (2012) once described MOOC platforms as the 'McDonaldisation of higher education', and following from this analogy we see MOOC platforms following monopolistic McDonaldstype expansion through 'glocalisation', where global corporates adapt to local preferences, eliminating local competition. This expansion in the name of diversity to increase market share poses further threats to marginalised knowledges and education systems.

\section{Commodification of Humans}

'The data have landed

First they said they needed data about the children

to find out what they're learning. Then they said they needed data about the children to make sure they are learning. Then the children only learnt what could be turned into data. Then the children became data.'

(Rosen 2018)

This poem aptly describes the fear of how the 'technological way-of-being' will come to control humans, turning us into mere data points. As Heidegger (1977) warned, 'enframing' humans as resources themselves - quantifying, predicting and commodifying them, defining what they are good for, rather than being good in and of themselves - begins to take humanity as a 'standing reserve' to be exploited in the same way natural resources are. As students agree to terms and conditions that allow their data to be used in exchange for access, we should question whether this data is fundamentally used to improve online pedagogy, or whether the 
goal is to make more marketable, valuable products for MOOC providers, their patrons and the third parties who they sell aggregate data to (Peterson 2015; edX 2018).

We already see that intangible, unquantifiable parts of education, like developing social skills, friendships, empathy, compassion and collaboration are typically not valued in institutional MOOCs. Instead, MOOCs are tracking large amounts of data, from individual mouse clicks to which part of videos are skipped or repeated (Qu and Chen 2015). When describing students, the types of MOOC data collected include gender, age and location to indicate their diverse reach, rather than student reflections and their varied experiences which would more likely improve the MOOC platform (Knox 2016, 103). Even when the data is put to well-intentioned use in terms of improving learning, the sample set is of predominantly more affluent, bacheloreducated Western students and do not represent the global population (Hansen and Reich 2015). Thus, MOOC data can have biased results, similar to that of racist facial recognition algorithms which have far greater accuracy identifying white people than black or Chinese people (Buolamwini and Gebru 2018).

\section{Conclusion}

By highlighting the coloniality embedded in dominant MOOC platforms, I argue that these platforms are promoting a form of 'digital neocolonialism' through the unidirectional transfer of standardised Western education to a diverse international pool of participants. Such MOOC platforms pose a further threat to dwindling heterogeneous, global knowledge systems (Czerniewicz et al. 2014, 124). MOOCs not only need to cater for difference in their conceptualisation of learners in terms of geographical and infrastructural contexts, but also create room for inclusion of different ways of thinking, knowing, and being. A key way of achieving this is supporting MOOC designers from different epistemic locations. 
Digital neocolonialism through MOOC platforms takes on new forms given contemporary issues of increasingly neoliberal techno-capitalist higher education systems whereby education and learners themselves are increasingly commodified. With trends towards paid online degrees, MOOCs seem to have departed from their initial aims of democratising access to education. As scalability is the goal, economic efficiency is promoted at the expense of quality learning experiences.

From a 'radical-reform' perspective, it is essential to make the online space, particularly MOOCs, more pluralistic through challenging epistemic injustices, such that existing power dynamics are acknowledged and addressed. However, from a 'beyond-reform' perspective, if more local and indigenous knowledges are put online and become accessible to all, who will benefit the most from these? Could this lead to exploitation of local knowledges through capitalistic agendas such as the commodification of culture? Could inclusion hinder alternative ways of being and knowing, particularly those that do not subscribe to technological or neoliberal ways of being? Further research is required into who actually benefits most from the inclusion of marginalised knowledges into the global knowledge base and the impacts of adverse incorporation.

\section{References}

Ali, Syed Mustafa. 2017. "Decolonizing Information Narratives: Entangled Apocalyptics, Algorithmic Racism and the Myths of History." Proceedings 1 (3): 50. https://doi.org/10.3390/IS4SI-2017-03910.

Altbach, Philip G. 2014. "MOOCs as Neocolonialism: Who Controls Knowledge?" International Higher Education 0 (75): 5-7. https://doi.org/10.6017/ihe.2014.75.5426.

Andreotti, Vanessa de Oliveira, Sharon Stein, Cash Ahenakew, and Dallas Hunt. 2015. "Mapping Interpretations of Decolonization in the Context of Higher Education | Decolonization: Indigeneity, Education \& Society," 21-40.

Bali, M, and S Sharma. 2017. "Envisioning Post-Colonial MOOCs: Critiques and Ways Forward." In Massive Open Online Courses and Higher Education: What Went Wrong, What Went Right and Where to Next?, 26-44. In R. Bennett \& M. Kent(eds).

Bayes-Brown, Gregg. 2014. "The Rise of EdX." Global University Venturing. 2014. https://globaluniversityventuring.com/the-rise-of-edx/.

Bhabha, Homi K. 1994. The Location of Culture. London: Routledge. 
Buolamwini, Joy, and Timnit Gebru. 2018. "Gender Shades: Intersectional Accuracy Disparities in Commercial Gender Classification." In Conference on Fairness, Accountability and Transparency, 77-91. http://proceedings.mlr.press/v81/buolamwini18a.html.

Cheney, Catherine. 2017. "The Road to Real Results for Online Learning in Developing Countries." Devex. April 3, 2017. https://www.devex.com/news/sponsored/the-roadto-real-results-for-online-learning-in-developing-countries-89884.

Christensen, Gayle, Andrew Steinmetz, Brandon Alcorn, Amy Bennet, Deirdre Woods, and Ezekiel Emanuel. 2013. "The MOOC Phenomenon: Who Takes Massive Open Online Courses and Why?" University of Pennsylvania, Philadelphia. http://www.voced.edu.au/content/ngv\%3A59592.

Cottom, Tressie. 2015. "Intersectionality and Critical Engagement with the Internet." SSRN Electronic Journal. https://doi.org/10.2139/ssrn.2568956.

Coursera. 2018. "African Cities : An Introduction to Urban Planning." Coursera. 2018. https://www.coursera.org/learn/african-

cities1?ranMID=40328\&ranEAID=SAyYsTvLiGQ\&ranSiteID=SAyYsTvLiGQ6_6vmjPj2gkdEcbD2ALXyA\&siteID=SAyYsTvLiGQ-

6_6vmjPj2gkdEcbD2ALXyA\&utm_content=10\&utm_medium=partners\&utm_sourc $\mathrm{e}=$ linkshare\&utm_campaign=SAyYsTvLiGQ.

Czerniewicz, Laura, Andrew Deacon, Janet Small, and Sukaina Walji. 2014. "Developing World MOOCs: A Curriculum View of the MOOC Landscape." Journal of Global Literacies, Technologies, and Emerging Pedagogies, Special Issue on MOOCs, 2 (3).

Danezis, George. 2014. "The Dawn of Cyber-Colonialism." Conspicuous Chatter (blog). June 21, 2014. https://conspicuouschatter.wordpress.com/2014/06/21/the-dawn-of-cybercolonialism/.

Dei, George Jerry Sefa, and Marlon Simmons. 2010. Fanon \& Education: Thinking Through Pedagogical Possibilities. Peter Lang.

Derry, Jan. 2008. “Technology-Enhanced Learning: A Question of Knowledge.” Journal of Philosophy of Education 42 (3-4): 505-19. https://doi.org/10.1111/j.14679752.2008.00638.x.

edX. 2018. "EdX Privacy Policy.” EdX. 2018. /edx-privacy-policy.

Enslin, Penny, and Kai Horsthemke. 2016. "Philosophy of Education: Becoming Less Western, More African?" Journal of Philosophy of Education 50 (2): 177-90. https://doi.org/10.1111/1467-9752.12199.

Fanon, Frantz. 1961. The Wretched of the Earth. London: MacGibbon \& Kee.

-. 2008. Black Skin, White Masks. Grove press.

Feenberg, Andrew. 1999. Questioning Technology. 1 edition. London; New York: Routledge.

Freire, Paulo. 1970. Pedagogy of the Oppressed. The Continuum International Publishing Group Inc.

Future Trends Forum. 2018. "What's next with EdX? - YouTube." 2018. https://www.youtube.com/watch?v=HwYNgnb0f3g.

FutureLearn. 2017. "Restricted Course Access for Learners in Some Countries." FutureLearn. April 16, 2017. https://about.futurelearn.com/blog/restricted-course-access.

2018a. “Africa: Sustainable Development for All?" FutureLearn. 2018. https://www.futurelearn.com/courses/africa-sustainable-development.

. 2018b. "Making Teacher Education Relevant for 21st Century Africa." FutureLearn. 2018. https://www.futurelearn.com/courses/teacher-education-africa.

2019. "Become a FutureLearn Partner." FutureLearn. 2019. https://www.futurelearn.com/partners/become-a-partner. 
Grosfoguel, Ramón. 2007. "The Epistemic Decolonial Turn.” Cultural Studies 21 (2-3): 21123. https://doi.org/10.1080/09502380601162514.

. 2011. "Decolonizing Post-Colonial Studies and Paradigms of Political Economy: Transmodernity, Decolonial Thinking, and Global Coloniality." Transmodernity 1 (1): $1-36$.

Hansen, John David Nadal, and Justin Reich. 2015. "Democratizing Education? Examining Access and Usage Patterns in Massive Open Online Courses" 350 (6265): 1245-48. https://doi.org/10.1126/science.aab3782.

Heidegger, Martin. 1977. "The Question Concerning Technology." Harper \& Row New York. Hickey, Sam, and Andries du Toit. 2013. "Adverse Incorporation, Social Exclusion, and Chronic Poverty." In Chronic Poverty: Concepts, Causes and Policy, edited by Andrew Shepherd and Julia Brunt, 134-59. Rethinking International Development Series. London: Palgrave Macmillan UK. https://doi.org/10.1057/9781137316707_7.

Hollands, Fiona M., and Devayani Tirthali. 2014. "Why Do Institutions Offer MOOCs?" Online Learning 18 (3). https://eric.ed.gov/?id=EJ1043160.

Hollington, Andrea, Tijo Salverda, Tobias Schwarz, and Oliver Tappe. 2015. Concepts of the Global South. Edited by Andrea Hollington, Tijo Salverda, Tobias Schwarz, and Oliver Tappe. Vol. 2015/1. Cologne, Germany: Global South Studies Center Cologne. http://www.uni-koeln.de/.

Holmwood, John. 2013. "Commercial Enclosure - Radical Philosophy." 2013. https://www.radicalphilosophy.com/commentary/commercial-enclosure.

Illich, Ivan. 2001. Tools for Conviviality. Marion Boyars.

Jansen, Jonathan. 2017. As by Fire: The End of the South African University. 1 edition. Tafelberg.

Knowledge Commons Brasil. 2014. "Digital Colonialism \& the Internet as a Tool of Cultural Hegemony | Knowledge Commons Brasil." 2014. http://www.knowledgecommons.in/brasil/en/whats-wrong-with-current-internetgovernance/digital-colonialism-the-internet-as-a-tool-of-cultural-hegemony/.

Knox, Jeremy. 2016. Posthumanism and the Massive Open Online Course: Contaminating the Subject of Global Education. Routledge. https://www.era.lib.ed.ac.uk/handle/1842/15895.

Kurban, Can, Ismael Peña-López, and Maria Haberer. 2017. "What Is Technopolitics? A Conceptual Schema for Understanding Politics in the Digital Age." IDP. Revista de Internet, Derecho y Política, May. https://doi.org/10.7238/idp.v0i24.3061.

Lane, J, and K Kinser. 2012. "MOOC's and the McDonaldization of Global Higher Education - WorldWise." The Chronicle of Higher Education (blog). 2012.

Lapping, Brian. 1987. Apartheid: A History. G. Braziller.

Laurillard, Diana. 2008. "Technology Enhanced Learning as a Tool for Pedagogical Innovation." Journal of Philosophy of Education 42 (3-4): 521-33. https://doi.org/10.1111/j.1467-9752.2008.00658.x.

Liyanagunawardena, Tharindu, Shirley Williams, and Andrew Adams. 2013. "The Impact and Reach of MOOCs: A Developing Countries' Perspective.” ELearning Papers, no. 33. http://centaur.reading.ac.uk/32452/.

Lockley, Pat. 2018. "Open Initiatives for Decolonising the Curriculum." In Decolonising the University, 145-73. Pluto Press.

Makgoba, Malegapuru, and Sipho Seepe. 2004. "Knowledge and Identity: An African Vision of Higher Education Transformation." In Towards an African Identity of Higher Education. Vista University.

Maldonado-Torres, Nelson. 2007. "On the Coloniality of Being." Cultural Studies 21 (2-3): 240-70. https://doi.org/10.1080/09502380601162548. 
2016. "Césaire's Gift and the Decolonial Turn.” In Critical Ethnic Studies, by Critical Ethnic Studies Editorial Collective, edited by Nada Elia, David M. Hernández, Jodi Kim, Shana L. Redmond, Dylan Rodríguez, and Sarita Echavez See, 435-62. Duke University Press. https://doi.org/10.1215/9780822374367-024.

Mamdani, Mahmood. 1996. Citizen and Subject: Contemporary Africa and the Legacy of Late Colonialism. Princeton Studies in Culture/Power/History. Princeton, N.J: Princeton University Press.

Martini, Beatrice. 2017. "Decolonizing Technology: A Reading List.” Beatrice Martini (blog). May 10, 2017. https://beatricemartini.it/blog/decolonizing-technology-reading-list/.

Mbembe, Achille. 2016. "Decolonizing the University: New Directions." Arts and Humanities in Higher Education 15 (1): 29-45. https://doi.org/10.1177/1474022215618513.

Model View Culture. 2016. "Data Colonialism: Critiquing Consent and Control in 'Tech for Social Change." Model View Culture (blog). 2016. https://modelviewculture.com/pieces/data-colonialism-critiquing-consent-and-controlin-tech-for-social-change.

MOOC List. 2018. "Search MOOC and Free Online Courses By Providers and Categories." MOOC List. 2018. https://www.mooc-list.com/initiatives-and-categories.

Patru, Mariana, and Venkataraman Balaji. 2016. "Making Sense of MOOCs: A Guide to Policy Makers in Developing Countries." UNESCO. 978-92-3-100157-4. http://unesco.ijs.si/261-2/.

Peterson, Rachel. 2015. "How MOOCs Threaten Your Privacy." Minding The Campus (blog). January 22, 2015. https://www.mindingthecampus.org/2015/01/22/how-moocsthreaten-your-privacy/.

Piron, Florence, Antonin Benoît Diouf, Marie Sophie Dibounje Madiba, Thomas Hervé Mboa Nkoudou, Zoé Aubierge Ouangré, Djossè Roméo Tessy, Hamissou Rhissa Achaffert, Anderson Pierre, and Zakari Lire. 2017. "Le libre accès vu d'Afrique francophone subsaharienne." Revue française des sciences de l'information et de la communication, no. 11 (August). https://doi.org/10.4000/rfsic.3292.

Portmess, Lisa. 2013. "Mobile Knowledge, Karma Points and Digital Peers: The Tacit Epistemology and Linguistic Representation of MOOCs." Canadian Journal of Learning and Technology 39 (2): r.

Qu, H., and Q. Chen. 2015. "Visual Analytics for MOOC Data." IEEE Computer Graphics and Applications 35 (6): 69-75. https://doi.org/10.1109/MCG.2015.137.

Rohs, Matthias, and Mario Ganz. 2015. "MOOCs and the Claim of Education for All: A Disillusion by Empirical Data." International Review of Research in Open and Distance Learning $16 \quad$ (6). http://search.proquest.com/docview/1770070648/abstract/28DB32F24ED7450FPQ/1.

Rosen, Michael. 2018. "Michael Rosen: The Data Have Landed." Michael Rosen (blog). February 8, 2018. http://michaelrosenblog.blogspot.com/2018/02/the-data-havelanded.html.

Said, Edward W. 1978. Orientalism. Peregrine Books. Harmondsworth: Penguin.

Santos, Boaventura de Sousa. 2014. Epistemologies of the South: Justice Against Epistemicide. 1 edition. London New York: Routledge.

Schlosser, Kolson. 2016. "Review Essay: Imagining the Techno-Capitalist Future(s) of Higher Education." Geoforum 72: 34-37. https://doi.org/10.1016/j.geoforum.2016.03.011.

Shah, Dawal. 2016. "XuetangX: A Look at China's First and Biggest MOOC Platform - Class Central." Class Central's MOOC Report. October 16, 2016. https://www.classcentral.com/report/xuetangx/. 
2017. "Massive List of MOOC Providers Around The World - Class Central." Class Central's MOOC Report. June 15, 2017. https://www.class-central.com/report/moocproviders-list/.

- 2018. "By The Numbers: MOOCs in 2018 - Class Central." Class Central's MOOC Report (blog). December 11, 2018. https://www.classcentral.com/report/mooc-stats2018/.

Simmons, Anjuan. 2015. "Technology Colonialism." Model View Culture (blog). 2015. https://modelviewculture.com/pieces/technology-colonialism.

Srnicek, Nick. 2017. "The Challenges of Platform Capitalism: Understanding the Logic of a New Business Model." Juncture 23 (4): 254-57. https://doi.org/10.1111/newe.12023.

Suarez-Villa, Luis. 2009. Technocapitalism: A Critical Perspective on Technological Innovation and Corporatism. Temple University Press. https://www.jstor.org/stable/j.ctt14btdwx.

Thiong'o, Ngugi wa. 1986. Decolonising the Mind: The Politics of Language in African Literature. London : Portsmouth, N.H: Heinemann Educational.

. 2005. "Europhone or African Memory: The Challenge of the Pan-Africanist Intellectual in the Era of Globalization1." In African Intellectuals: Rethinking Politics, Language, Gender and Development, 155-65. CODESRIA. http://africa.peacelink.org/wajibu/articles/art_7516.html.

Thomson, Iain D. 2001. Heidegger on Ontotheology: Technology and the Politics of Education. Cambridge; New York: Cambridge University Press.

Trines, Stefan. 2018. "Educating the Masses: The Rise of Online Education in Sub-Saharan Africa and South Asia." WENR. August 14, 2018. https://wenr.wes.org/2018/08/educating-the-masses-the-rise-of-online-education.

Udemy. 2018. “Top Learning a Foreign Language Courses Online." Udemy. 2018. https://www.udemy.com/topic/learning-a-foreign-language/.

Ulrich, Otto. 1992. "Technology." In The Development Dictionary: A Guide to Knowledge As Power, edited by Wolfgang Sachs. London; Atlantic Highlands, N.J: Zed Books.

Vaditya, Venkatesh. 2018. "Social Domination and Epistemic Marginalisation: Towards Methodology of the Oppressed." Social Epistemology 32 (4): 272-85. https://doi.org/10.1080/02691728.2018.1444111.

Walters, Patrick, and Rita Kop. 2009. "Heidegger, Digital Technology, and Postmodern Education: From Being in Cyberspace to Meeting on MySpace." Bulletin of Science, Technology \& Society 29 (4): 278-86. https://doi.org/10.1177/0270467609336305.

Ware, Gemma. 2014. "Online Learning Pioneer Slams Ban on Iranian, Cuban, Sudanese Students." The Conversation. 2014. http://theconversation.com/online-learningpioneer-slams-ban-on-iranian-cuban-sudanese-students-24581.

Warschauer, Mark. 2003. Technology and Social Inclusion: Rethinking the Digital Divide. Cambridge, Mass. ; London: MIT Press.

Wiley, D. 2011. “Open Content.” 2011. http://opencontent.org/definition/. 